\title{
HABILIDADE SOCIAL EDUCATIVA DE DAR E RECEBER FEEDBACK: UM CONSTRUTO POTENCIALIZADOR DE APRENDIZAGENS NA FORMAÇÃO DE EDUCADORES
}

\author{
BRUNA KEDMAN NASCIMENTO DE SOUZA LEÃO \\ Graduada em Pedagogia pela Universidade Federal da Paraíba (UFPB). Especialista em \\ Psicopedagogia Institucional pelo Centro Integrado de Tecnologia e Pesquisa (CINTEP). \\ Atualmente é mestranda em Educação na UFPB e Bolsista CAPES/FAPESQ - BRASIL. E-mal: \\ brunakedmanl@gmail.com \\ https://Orcid.Org/0000-0002-4108-7371

\section{FERNANDO CÉZAR BEZERRA DE ANDRADE} \\ Graduado em Psicologia, Filosofia e Letras. Mestre e Doutor em Educação. Professor da \\ Universidade Federal da Paraíba (UFPB). Endereço Profissional: Universidade Federal da Paraíba \\ - Centro de Educação - Departamento de Fundamentação da Educação - Campus I - João Pessoa \\ - PB. E-mail: frazec66@ gmail.com - https://Orcid.Org/0000-0003-0554-2514
}

\section{ANA PAULA HENRIQUE CAVALCANTE}

Graduada em Letras Inglês pela Universidade Federal da Paraíba (UFPB). Mestra em Educação pela Universidade Federal da Paraíba (UFPB). Atualmente é professora de língua inglesa na Educação Infantil. E-mail: anapaulahenriquecavalcante@ gmail.com - https://Orcid.Org/00000002-5984-9864

\section{RESUMO}

Analisa-se a relação entre o uso da habilidade social de dar e receber feedback e a elevação de níveis de desempenho acadêmico de três discentes, no contexto de um módulo avaliativo do componente curricular de Filosofia da Educação de um curso de formação inicial em Pedagogia, durante um semestre letivo de 2015. Recorrendo-se à pesquisa qualitativa, fez-se uma análise dos desempenhos discentes em um módulo avaliativo, considerados antes e após a apresentação de cinco feedbacks nos termos descritos pela Teoria das Habilidades Sociais. Evidenciou-se elevação nas notas obtidas, sugerindo o aumento do potencial para aprendizagens, associado às interações verbais mais frequentes e individualizadas. Sugere-se a participação em atividades para a aprendizagem da habilidade de Dar e Receber Feedback na formação inicial de pedagogos(as).

Palavras-chave: Habilidade Social Educativa Dar e Receber Feedback. Avaliação. Formação inicial em Pedagogia.

\section{THE SOCIAL AND EDUCATIVE ABILITY OF FEEDBACK GIVING AND RECEIVING: A POTENTIAL LEARNING CONSTRUCTOR IN TEACHERS' TRAINING}

\begin{abstract}
This article contains an analysis of the relationship between the use of social able feedbacks and the high-performance levels of three students, in the context of an evaluation module of the curriculum component of Philosophy of Education. This component was part of an initial formation course of Pedagogy during a semester of 2015. Through qualitative research, the students' performance was analysed on the evaluate module, considered before and after the introduction of five feedbacks according to the Social Skills Theory. The results revealed an elevation on the students' grades, suggesting an increase of learning potential, associated with more frequent and individualized verbal interactions. In conclusion, it is proposed to take part in activities to learn the skill of Accepting and Giving Feedback social skill on the pedagogues' initial formation.
\end{abstract}

Keywords: Accepting and Giving Feedback Educational Social Skill. Evaluation. Pedagogy initial formation. 


\section{HABILIDAD SOCIAL EDUCATIVA DE DAR Y RECIBIR FEEDBACK: UN CONSTRUTO POTENCIALIZADOR DE APRENDIZAJES EN LA FORMACIÓN DE EDUCADORES}

\section{RESUMEN}

Se analiza la relación entre el uso de la habilidad social de dar y recibir feedback y la elevación de niveles de desempeño académico de tres discentes, en el contexto de un módulo de evaluación del componente curricular de Filosofía de la Educación de un curso de formación inicial en Pedagogía de un semestre lectivo de 2015. Recurriendo a la investigación cualitativa, se hizo análisis de los resultados discentes en un módulo de evaluación, considerados antes y después de la presentación de cinco feedbacks en los términos descritos por la Teoría de las Habilidades Sociales. Se evidenció elevación en las notas obtenidas, sugiriendo el aumento del potencial para aprendizajes, asociado a las interacciones verbales más frecuentes e individualizadas. Se sugiere por la participación en actividades para el aprendizaje de la habilidad de Dar y Recibir Feedback en la formación inicial de maestros.

Palabras clave: Habilidad Social Educativa Dar y Recibir Feedback. Evaluación. Formación Inicial en Pedagogía.

\section{Introdução}

A influência dos componentes afetivos, culturais e sociais se dispõe de forma simultânea em nossas ações. Porém, estes componentes nem sempre foram reconhecidos nos processos educativos não formais e, menos ainda, em contextos de educação formal.

Associar os processos de educação formal aos aspectos relacionais é afirmar a educação como um processo civilizatório, fundamentalmente humano, requisito para que os nela envolvidos tenham condições de intervir na realidade na qual estão inseridos, conhecendo seus direitos, deveres e possibilidades, assim como saibam lidar, conviver e estabelecer relacionamentos harmônicos com outrem.

Os ambientes de educação formal, escolas e universidades, além de transmitirem conhecimentos e saberes historicamente construídos, também atuam diretamente na modelação de comportamentos, a fim de educarem os indivíduos para a vida social e profissional. Nesse sentido, tais instituições tomam como atividade central o processo de educar, implicando igualmente em reeducar e (des)construir padrões comportamentais de interação. No contexto de formação de professores(as), a aprendizagem de conteúdos relacionais é fulcral.

Docentes precisam renovar-se para ensinar - pois aprendizagem é mudança e supõe, da docência, também transformações contínuas: daí a metáfora de Carbonell (2016), para quem docentes do século XXI precisam ser transformadores intelectuais. Com tal fim, 
esses profissionais necessitam desenvolver uma série de habilidades interpessoais para manejarem a interação e, em particular, a comunicação com outras pessoas.

Segundo Soares e Del Prette (2015) a formação na universidade deve promover tanto competências analíticas, processos cognitivos de raciocínio e aprendizagem, como também competências interpessoais requeridas de acordo com a profissão. No caso da formação em Pedagogia, essa reflexão torna-se ainda mais relevante, por conta do campo tradicional de atuação, envolvendo, na escola regular, a infância e a adolescência. Ora, se, como argumentado até aqui, o trabalho da Pedagogia é interativo, relacional e alcança o tempo mais propício à aprendizagem de habilidades sociais - o início da vida escolar -, torna-se precípua a formação de pedagogos(as) socialmente hábeis.

As Habilidades Sociais são um conjunto de desempenhos que compõem o repertório comportamental do sujeito em situações interpessoais (DEL PRETTE; DEL PRETTE, 1999): logo, num contexto educativo, essas habilidades poderão qualificar positivamente o relacionamento entre docentes e discentes, facilitando, em especial, a construção de Habilidades Sociais Educativas, que objetivam o desenvolvimento e aprendizagem do outro, em situações formais ou informais, possibilitando mudanças positivas em desempenhos e comportamentos (DEL PRETTE; DEL PRETTE, 2003). Incorporar essas habilidades em contexto formativos favorece a convivência pró-social e, com ela, a aprendizagem dos(as) envolvidos(as).

As Habilidades Sociais Educativas estão organizadas em classes e subclasses de habilidades que subsidiam a tarefa educativa, seja a de familiares e responsáveis ou professores(as). Dentre as classes está a de Monitorar Positivamente e, nela, está a subclasse de Dar e Receber Feedback, a qual consiste numa descrição verbal do(a) docente em relação a comportamentos observáveis emitidos por discentes (DEL PRETTE; DEL PRETTE, 2008). Com efeito, essa habilidade possibilita a construção de um relacionamento dialógico entre docentes e discentes, suscitando maiores chances de aprender.

A aplicabilidade dessa habilidade pode efetivar processos pedagógicos, dentre eles a avaliação. Envolvendo cuidado e confiança no contexto do relacionamento interpessoal docente-discente, conforme Demo (2006), a avaliação é uma atividade constante no processo de ensino-aprendizagem. Assim, a Habilidade Social Educativa de Dar e Receber Feedback consiste, para quem o envia, na descrição verbal do comportamento emitido pelo sujeito destinatário da devolutiva, estando intimamente 
relacionada à avaliação, já que, se bem executada, pode funcionar como um construto potencializador do processo de mudanças do comportamento ou desempenho examinado.

A literatura sobre o feedback (POERTNER; MILLER, 1996; DEL PRETTE; DEL PRETTE, 1999; SPENCE, 2003; ZEFERINO, 2007) permite classificá-lo como positivo ou negativo; ora, se no senso comum o positivo está associado ao bom e o negativo, ao ruim, aqui, a habilidade educativa de Dar e Receber Feedback sempre terá o objetivo de melhorar desempenhos, de modo que o feedback é positivo quando possui a intenção de manter um desempenho e negativo, quando pretende corrigi-lo. Esses dois aspectos podem com frequência andar juntos, como destacam os termos de Spence (2003, p.91 - tradução livre), segundo quem "o feedback deve ser fornecido de modo construtivo, enfatizando os aspectos positivos do desempenho e indicar os aspectos que precisam de mudança”.

Conforme quem dá o feedback, ele envolve um modelo significativo - na sala de aula, docente e, como neste estudo, discente no exercício da monitoria -, mas também colegas e, quando a autorregulação já está presente (como presumidamente é o caso de universitários), a própria pessoa cujo comportamento está sob avaliação.

Para verificar as contribuições da habilidade social educativa de Dar e Receber Feedback em desempenhos avaliativos e, consequentemente, na formação daqueles(as) pedagogos(as), aqui se analisa a evolução no desempenho escrito - identificada nas produções em exercício avaliativo antes e após feedback no componente curricular de Filosofia da Educação, no primeiro semestre letivo de 2015 - de três estudantes de Pedagogia (modalidade presencial) de uma universidade pública. Para corroborar a análise, também foram considerados o repertório comportamental de cada estudante, mais especificamente sua participação oral nas aulas.

Cumpre esclarecer: a primeira autora deste artigo atuou como monitora e, junto ao respectivo docente, fornecedora dos feedbacks cuja repercussão é interpretada. Assim, em conformidade com a Teoria das Habilidades Sociais, a habilidade de Dar e Receber Feedbacks é examinada em seus efeitos, mas também em sua topografia (ou seja, na qualidade com que as devolutivas foram fornecidas, levando-se em conta suas variações correspondentes às especificidades das condutas discentes recebedoras do feedback). Devese destacar, no contexto desta pesquisa o lugar único do(a) discente monitor(a), pois funciona, concomitantemente, fornecendo feedbacks tanto enquanto par como modelo que se aproxima do(a) docente a quem assessora. 
Vale salientar: a escolha pela pesquisa envolvendo a formação inicial de pedagogos(as) foi motivada pela importância de evidenciar a Pedagogia como profissão dedicada, no Brasil, aos primeiros anos de escolarização - durante os quais a infância e o início da adolescência fazem-se presentes, tempos esses fundamentais para a formação de habilidades sociais necessárias à convivência e à aprendizagem. Como destacam Elias e Amaral (2016), a formação de habilidades sociais nesses anos é um fator de proteção contra riscos de desenvolvimento de problemas de comportamento e dificuldades de aprendizagem evitáveis - esse dado sublinha a responsabilidade particular de pedagogos(as) na educação infantil e nos primeiros anos do ensino fundamental. Não obstante, suas considerações são extensíveis para a formação docente de modo geral.

\section{Habilidades sociais e habilidades sociais educativas no processo de ensino- aprendizagem}

Segundo Tardif (2013), a interação é parte constitutiva do trabalho docente, ou seja, o processo de ensino-aprendizagem se desenvolve por meio de situações interativas. Essas interações ocorrem de modo natural, visto que o ser humano, por sua condição social, necessita do outro e do ambiente (contexto) para desenvolver-se e aprender.

A partir da classificação apresentada por Zabala (1998), é possível reconhecer, mesmo nos conteúdos de ensino, um caráter de interatividade e diversidade: conteúdos factuais (relativos ao conhecimento dos fatos, como no ensino de história); procedimentais (relacionados ao saber fazer, a procedimentos e habilidades, como sintetizar um texto); conceituais (concernentes à compreensão de conceitos, definições); e os atitudinais (referentes ao aprender a ser, a desenvolver atitudes, comportamentos, internalizar valores, saber lidar e conviver com outrem) - todos eles apontam para a aprendizagem em contexto social e, no caso da sala de aula, de interações docente-discente.

Do conjunto dessas interações resulta o que se chama de relacionamento: no caso do processo de ensino-aprendizagem, é estabelecido o relacionamento docente-discente, cuja harmonia é mantida quando, principalmente, aprendizagens são proporcionadas. Nesse cenário, o(a) professor(a) precisa compreender seu papel de agente educativo, como "pessoa que promove, de maneira regular ou ocasional, o processo de aprendizagem e/ou desenvolvimento de outras" (DEL PRETTE; DEL PRETTE, 2008, p. 519).

Então, recorrendo ainda à classificação de Zabala (1998), além de dominar o conteúdo (aprender uma série de conteúdos conceituais), o(a) docente precisa aprender, em 
sua formação (inicial e continuada) habilidades que lhe permitam relacionar-se de forma socialmente hábil com seus alunos e alunas, desenvolver posturas e comportamentos pessoais e profissionais concorrendo para sua competência social enquanto interage no seu trabalho. Parte significativa da tarefa docente, com seu caráter interativo, relacional e comunicativo, requer do(a) educador(a) o desenvolvimento de habilidades específicas, possibilitando a articulação e o acionamento de dimensões cognitivas, sociais, culturais e afetivas. Tratam-se das habilidades sociais e das habilidades sociais educativas

As habilidades sociais são, segundo Del Prette e Del Prette (2005), um conjunto de desempenhos que constituem o repertório comportamental diante de situações interpessoais e favorecem o estabelecimento de relacionamentos saudáveis, amistosos, entre os sujeitos. Essas habilidades são de cunho pessoal, cultural e situacional, ou seja, seu manejo dependerá da situação na qual estão os interlocutores envolvidos na relação; quando manejadas no relacionamento interpessoal professor-aluno, facilitam o desenvolvimento da aprendizagem, além de qualificarem positivamente as relações estabelecidas.

Segundo Del Prette e Del Prette (1999, p. 47), o comportamento só será caracterizado como socialmente competente se alcançar simultaneamente os seguintes critérios:

(a) consecução dos objetivos de uma situação interpessoal; (b) a manutenção ou melhoria de sua relação com o interlocutor, incluindo-se aí a busca de equilíbrio do poder e das trocas nessas relações; (c) manutenção ou melhoria da autoestima; (d) manutenção ou ampliação dos direitos humanos socialmente estabelecidos.

O educador será socialmente competente quando, em sua prática pedagógica, conseguir, no uso de suas habilidades sociais, alterar e melhorar os comportamentos e desempenhos de seus educandos e educandas. Por exemplo: uma namorada chega sempre pontualmente nos encontros marcados, mas não seu namorado, que toda vez atrasa. Neste caso, a namorada é socialmente habilidosa, pois chega no horário combinado, porém não é socialmente competente, pois não conseguiu modificar o comportamento do namorado. Nesse sentido, enquanto as habilidades sociais são de caráter descritivo, a competência social é de caráter avaliativo, observável em relações nas quais o sujeito emite comportamentos assertivos (DEL PRETTE; DEL PRETTE, 1999).

A assertividade, conceito mais importante no rol das Habilidades Sociais, é entendida como uma habilidade que possibilita o reconhecimento dos próprios direitos e de outrem, a liberdade de expressar pensamentos, sentimentos, crenças e princípios sem 
anular ou impedir o outro (DEL PRETTE; DEL PRETTER, 1999); nesse sentido, pode-se fazer uma conexão entre ela e a dialogicidade, o ir e vir constante e respeitoso entre os envolvidos em contextos de conversação, negociação e trocas inerentes ao ensinoaprendizagem.

Por tratarem-se de um campo amplo, as habilidades sociais são divididas em classes e subclasses específicas, de acordo com cada contexto e situação interpessoal. No caso das interações ocorridas nas relações de ensino-aprendizagem, existem as Habilidades Sociais Educativas: elas são fulcrais para compor a competência social de educadores(as) (DEL PRETTE; DEL PRETTE, 1998), sobretudo, em contextos de formação docente. A literatura sobre as habilidades sociais educativas (DEL PRETTE; DEL PRETTE, 2003; 2005; 2008) destaca: elas compõem um repertório que pode (e muitas vezes precisa) surgir com a análise da própria prática profissional, com apoio de programas de formação docente (PINOLA; MATURANO; ELIAS; DEL PRETTE, 2017).

Assim, as habilidades sociais educativas também são organizadas por Del Prette e Del Prette (2008) em classes e subclasses. Essa organização ou divisão deve-se à especificidade das habilidades sociais em cada contexto ou situação interpessoal, pois possuem as já referidas dimensões pessoal, cultural e situacional (DEL PRETTE; DEL PRETTE, 1999). Este trabalho, dentro do grupo das habilidades sociais educativas, analisa dados associados à classe de Monitorar Positivamente.

Ora, segundo Del Prette e Del Prette (2008), um critério-chave para caracterizar-se uma ação como educativa numa sequência didática, por exemplo, é a verificação da aprendizagem (ou seja, se houve aprendizagem discente). A avaliação da aprendizagem tem, assim, um papel decisivo na verificação da competência social educativa de docentes, sendo um de seus requisitos conhecer o perfil de aprendizagens do alunado.

Logo, o(a) professor(a) precisa elaborar instrumentos avaliativos que lhe permitam conhecer sua turma, no tocante às suas fragilidades e potencialidades relativas aos conteúdos e objetivos de ensino e, a partir desses aspectos, nortear e remodelar sua prática, visando à aprendizagem e ao desenvolvimento daquele alunado específico. Será sempre uma avaliação individual, situada e dirigida para a aprendizagem, como um de seus facilitadores (PINOLA; MATURANO; ELIAS; DEL PRETTE, 2017).

Nesse cenário, a habilidade social educativa de Dar e Receber Feedback suscita o desenvolvimento do automonitoramento, "uma habilidade metacognitiva e afetivocomportamental pela qual a pessoa se observa, descreve, interpreta e regula seus 
pensamentos, sentimentos e comportamentos sociais" (DEL PRETTE; DEL PRETTE, 2001, p. 62); ou seja, pensar e administrar o próprio pensamento e, sobretudo, a própria prática, aproxima-se da práxis pedagógica a ser compreendida e desenvolvida na formação inicial de docentes.

\section{Habilidade social educativa dar e receber feedback}

Na classe de Monitorar Positivamente, que consiste no comportamento verbal ou não verbal do(a) educador(a) para administrar ou mediar comportamentos observáveis ou relatados pelos(as) alunos(as), está a habilidade social educativa Dar e Receber Feedback, consistindo numa descrição verbal acerca de desempenhos emitidos por um sujeito, feita por pessoas do ambiente no qual se insere aquele sujeito.

Cabe observar: apesar de o conceito dessa habilidade atestar seu caráter verbal, acredita-se na emissão do feedback também em forma de gestos, pois o corpo fala. Os gestos estão imbricados no componente comportamental não verbal das habilidades sociais, referindo-se a aspectos diretamente observáveis (DEL PRETTE; DEL PRETTE, 1999). Então, num contexto educativo, um gesto do(a) educador(a) transmite uma informação, podendo motivar ou desmotivar seus alunos e alunas. Entende-se, pois, o viés formador e pedagógico do gesto dentro de processos de ensino-aprendizagem.

Outros autores (ZEFERINO, 2007; POERTNER; MILLER, 1996) referem-se ao feedback como um construto indispensável no processo de formação e cotidiano profissional. Segundo Zeferino (2007), o feedback funciona como um retorno ou uma informação detalhada, criteriosa, acerca de um desempenho comportamental em alguma situação, além de ajudar o(a) estudante a tornar-se mais autodiretivo(a) em sua formação.

Quando essa informação consegue ou ajuda a remodelar, alterar positivamente o desempenho, pode-se dizer que houve aprendizagem: nesse sentido, "a ação educativa implica em avaliação e monitoramento dos efeitos desses comportamentos sobre o educando" (DEL PRETTE; DEL PRETTE, 2008, p. 520). Desse modo, a habilidade social educativa de Dar e Receber Feedback funciona como parte precípua do ensino, por dar pistas a quem ensina (e dá feedback) e quem aprende (e os recebe) sobre a qualidade e o andamento do processo em comum.

Nesse sentido, emitir e receber feedback estão diretamente relacionados à disponibilidade, flexibilidade, habilidade para ouvir, ensinar e aprender com o outro. Poertner e Miller (1996) enfatizam que, para surtir os efeitos esperados, a responsabilidade 
não é apenas de quem fornece o feedback, mas também de quem o recebe. Assim, tanto o(a) educador(a) quanto o(a) educando(a) precisam estar abertos, disponíveis para ensinar e aprender simultaneamente.

Ora, o feedback, enquanto habilidade social educativa, pode ser classificado como positivo ou negativo. Desse modo, o feedback é positivo quando possui a intenção de manter um desempenho e negativo, quando pretende corrigi-lo (DEL PRETTE; DEL PRETTE, 2008). Ambos os tipos de feedback foram fornecidos e recebidos nos desempenhos discentes analisados nesta pesquisa.

O processo educativo é claramente um exercício dialógico, dinâmico, interativo e social. Utilizar esta habilidade em processos avaliativos proporciona o aprimoramento do aprendizado profissional e pessoal, tanto de educadores(as) como de estudantes. É o que será evidenciado a seguir, com dados coletados em uma turma de discentes de uma licenciatura em Pedagogia de universidade pública brasileira.

\section{Procedimentos metodológicos}

Para verificar-se a hipótese de que a Habilidade Social Educativa de Dar e Receber Feedback contribui em processos avaliativos foram elaborados e fornecidos feedbacks em desempenhos de uma turma de primeiro período do curso de Pedagogia, de uma universidade pública, no componente curricular de Filosofia da Educação, na qual a primeira autora deste artigo foi monitora, no primeiro semestre letivo de 2015. A turma era composta por vinte e quatro estudantes, destes, apenas seis refizeram os exercícios.

O estudo caracterizou-se como pesquisa-ação, haja vista que a investigação promoveu mudanças individuais das pessoas daquele meio social (ÉVORA, 2006). A primeira autora deste artigo, enquanto monitora da disciplina, interveio no processo de fornecimento de feedbacks e também pôde rever a própria prática, por meio das devolutivas dos estudantes tanto na dinâmica das aulas como no próprio instrumento avaliativo. A pesquisa possui, portanto, uma abordagem qualitativa, avaliou-se qualitativamente os desempenhos dos estudantes antes e depois do fornecimento do feedback.

Ressalta-se: a utilização dessa habilidade social educativa em desempenhos avaliativos corrobora o aprendizado do(a) estudante e do(a) docente. Segundo Spence (2003), o feedback é eficaz quando emitido por alguém significativo (modelo): no estudo em questão, professor e monitora funcionaram como administradores significativos do 
processo - sendo a monitora uma figura mais acessível aos estudantes, que com ela se identificaram por sua condição horizontal na relação de poder, enquanto discente. Presume-se, nesse sentido, que a recepção do feedback emitido pela monitora foi favorecida desse modo, visto que, com o caráter de avaliação, esse dispositivo frequentemente é associado ao caráter punitivo com que a atividade avaliativa tradicionalmente o emprega.

Houve ocasião para praticar a habilidade de Dar e Receber Feedback 48 vezes, por escrito, em instrumentos avaliativos construídos pelo docente ao longo do semestre. Desse modo, cada estudante pôde rever seu desempenho, manter ou alterar aspectos que foram apontados em seu feedback, objetivando alcançar os objetivos de aprendizagem. Neste artigo, foram analisados os desempenhos pré e pós-feedback de três estudantes, chamados de E1(Estudante 1), E3(Estudante 3) e E5(Estudante 5).

Tais desempenhos foram escolhidos visto que, inicialmente, E1 apresentou problemas na escrita, compreensão do conteúdo e organização do pensamento no primeiro momento do exercício: como se verá, a partir da inserção do feedback, conseguiu evoluir qualitativamente. E2, por sua vez, foi uma aluna que, mesmo tendo superado a média no primeiro momento, preocupou-se em refazer e melhorar seu desempenho. Detectou-se plágio na síntese da estudante E3, situação tratada pedagogicamente por meio da emissão do feedback. Como será demonstrado, esses três desempenhos evidenciaram, com suas especificidades, os ganhos do feedback no processo de ensino-aprendizagem.

Nessa investigação, utilizou-se para análise apenas o processo de feedback apresentado ao primeiro exercício avaliativo, da primeira unidade. A escolha desse exercício justifica-se pelo fato de ter sido produzido e entregue pelos(as) estudantes em meio digital, facilitando, com isso, corrigir, construir e fornecer o feedback; além disso, o instrumento elaborado requeria de cada estudante a capacidade de sintetizar textos, crucial na formação acadêmica. Ele possibilitou perceber aspectos que resultaram em breves discussões concernentes à influência da educação básica na formação profissional.

Foi concedido o tempo de uma semana para os(as) estudantes refazerem o exercício sob a orientação do feedback. Apenas seis estudantes entregaram o exercício refeito e, para analisar a evolução de desempenho dos(as) estudantes, foram selecionadas cinco do primeiro exercício de avaliação - uma síntese de um dos textos estudados na disciplina: “A cabeça-bem feita", segundo capítulo do livro A cabeça bem-feita: repensar a reforma reformar o pensamento, de Edgar Morin (2006). Os(As) estudantes puderam fazer essa 
tarefa em casa, onde tiveram mais tempo para pensar e refletir. Esse aspecto precisa ser considerado na formulação dos critérios avaliativos, pois o(a) estudante teve possibilidade pesquisar noutras fontes a fim de clarificar a própria compreensão.

O feedback foi fornecido por escrito para cada questão da síntese entregue pelos(as) estudantes, reforçando os aspectos satisfatórios (feedback positivo) e reorientando os que precisavam ser revistos (feedback negativo). Para estes, foram dadas sugestões, possíveis caminhos para os(as) estudantes terem informações suficientes e melhorarem sua tarefa.

Vale salientar: na prática da emissão de feedback, os primeiros são mais detalhados e, com o passar do tempo, diminuem-se as informações de modo ao próprio autor da tarefa poder identificar quais aspectos precisam ser melhorados. Isso porque se acredita na autonomia formativa, ou seja, a inserção de uma habilidade social (Dar e Receber Feedback) possibilita a aprendizagem de outra: a automonitoria.

Esta última habilidade, além de permitir ao sujeito ser consciente de suas potencialidades, vulnerabilidades, analisar e compreender relacionamento e possíveis problemas interpessoais; também proporciona melhora na autoestima (fundamental no processo de aprendizagem) e autoconfiança (DEL PRETTE; DEL PRETTE, 2001). Percebe-se contribuírem ambas habilidades não apenas para procedimentos acadêmicos, mas para a formação da pessoa.

O fornecimento do feedback indica, sobretudo, que o(a) professor(a) está atento(a), cuidando do aprendizado de seu alunado; este, por conseguinte, também passará a preocupar-se mais com suas produções, assim como aprenderá a fornecer feedbacks ao desempenho do(a) professor(a).

$\mathrm{Na}$ perspectiva de Zeferino (2007), um feedback é bom quando é assertivo, respeitoso, descritivo, oportuno e específico. Esses aspectos foram considerados na elaboração dos feedbacks desta pesquisa, pois, de acordo com Del Prette e Del Prette (2003), tanto o feedback positivo como o negativo objetivam melhorar o desempenho e/ou comportamento.

Os aspectos analisados em cada exercício foram: o conteúdo estudado (temática estudada no texto assim como a identificação do problema, tese, ideias principais e articulações com a realidade); as habilidades de escrita (ortografia e organização das ideias); e a estética do trabalho. Observou-se a evolução de cada estudante quanto a esses aspectos após a emissão do feedback. 
Sob a orientação do feedback ao primeiro exercício escrito, dos vinte e quatro estudantes frequentando as aulas, apenas seis refizeram o exercício de síntese de texto. É importante ressaltar: apesar do pequeno número de devolutivas escritas, os(as) estudantes davam retorno verbal acerca das conduções dos feedbacks durante as aulas, referindo-se ao instrumento propriamente dito ou por meio de comportamentos possivelmente influenciados pela nova prática.

Outra hipótese explicativa para o pequeno número de exercícios refeitos está relacionada à possível desmotivação de discentes para atividades, em função de longa greve de docentes do ensino superior ${ }^{1}$. Embora o feedback tenha sido fornecido após esse período, o afastamento da rotina acadêmica pode ter desmotivado os(as) universitários(as) a prosseguirem. A motivação, fundamental dentro do processo de ensino-aprendizagem (MARCHESI, 2006), depende de cuidado, estímulo e, sobretudo, manutenção do contato entre docente e discentes. Além disso, ser motivado, segundo esse mesmo autor, também está associado às metas e interesses do sujeito: logo, numa ocasião avaliativa, se alcançar uma nota dentro da média for a meta principal, pode não haver motivação suficiente para refazer o exercício e, com isso, melhorar o desempenho e, consequentemente, a aprendizagem.

O aprofundamento da análise de desempenho das três sínteses de texto refeitas a partir do feedback fez-se conforme os seguintes aspectos: o conteúdo estudado (conceitual e procedimental), a habilidade de escrita e a estética do trabalho. Para apreciar os efeitos do feedback foi observada evolução de cada estudante entre a síntese de texto (préfeedback) e sua devolutiva (pós-feedback).

A nota atribuída à devolutiva foi construída pela média das notas pré e pósfeedback. Por exemplo, se o(a) estudante obteve nota 6,0 no primeiro momento do exercício e 7,0 no segundo, a nota de sua síntese refeita foi 7,5.

A evolução discente, demonstrada quantitativamente (por meio das notas) e qualitativamente (pela discussão desenvolvida com aspectos apresentados nos desempenhos escritos e os comportamentos emitidos em sala), evidencia a importância do feedback no processo avaliativo, por aumentar as chances de sucesso na vida acadêmica de quem ensina, assim como por manter a competência social e interpessoal de quem aprende.

\footnotetext{
${ }^{1}$ Ocorrida por aproximadamente quatro meses em 2015, atrasando a conclusão desse semestre letivo, ocorrida apenas em 2016.
} 


\section{Resultados e discussão}

A síntese de texto solicitava interpretar o texto "A cabeça bem feita", de Edgar Morin (2006) por meio de respostas a três perguntas: “De que trata o texto?”, “Quais são o problema e a tese do autor nesse texto?", “Quais são as ideias principais?”. Em seguida, solicitava-se, por meio de três enunciados, comentários ao texto, indicadas conexões do texto com experiências $\mathrm{da}(\mathrm{o})$ respondente e, por fim, a conclusão do texto. A seguir, serão apresentados os perfis e aspectos dos desempenhos de cada estudante antes e após o feedback, e, com isso, a evolução quantitativa entre os dois momentos.

\section{Estudante 1}

E1 era assíduo, participativo nas discussões em sala, mas apresentava confusão de ideias e desorganização das palavras em sua fala. Esses aspectos apareceram em sua síntese de texto: desorganização estética e pouco domínio do conteúdo teórico estudado. Embora o exercício de síntese tenha sido realizado em Word, programa de edição de textos da Microsoft útil para organizar o aspecto formal do texto (estilos e tamanhos de fonte, paragrafação e entre outros), E1 entregou sua síntese com fontes diferentes (estilos, tamanhos e cores). Houve também a utilização das palavras do autor sem a devida referência, podendo-se sugerir, de um lado, o desconhecimento parcial das normas técnicas para a citação de textos, mas, de outro, também, insegurança em relação ao conteúdo estudado, como pode-se verificar em suas respostas:

2. Quais são o problema e a tese do autor nesse texto? "O que é uma cabeça bem-feita?" - "Uma aptidão geral para colocar e tratar os problemas, ligando os saberes, lhes dando sentido."

3. Quais são as ideias principais? Comente-as. "Uma cabeça bem-feita é uma cabeça apta a organizar os conhecimentos e, com isso, evitar sua acumulação estéril." Em outras palavras fazer conexões e dar sentido as [sic] ideias para que tenham significado, trazendo como experiências aquilo que realmente possa [sic] formar uma cabeça bem-feita, o que se pode ficar como conhecimento e o que se deve excluir para evitar acúmulo de informação desnecessária.

O desconhecimento verifica-se na medida que, mesmo aspeando os trechos citados, não acrescenta itens obrigatórios, como página, autor, ano, após a citação direta. Nesse sentido, das aspas infere-se a honestidade intelectual de E1, ao assumir empregar as palavras de outro; porém, isso não era suficiente para atender aos critérios de um texto acadêmico bem escrito. Ademais, repetir predominantemente palavras de modo literal ("cabeça", "bem feita", “conhecimento", "acúmulo"), em geral, adota-se em duas circunstâncias: quando o autor escreve de sorte a não precisar ser parafraseado; ou quando 
o comentarista (no caso, E1) não consegue assimilar o argumento sintetizado e discutido, nem, por consequência, interpreta o texto, associando-o a suas ideias, por exemplo.

Assim, neste último caso, como pareceu ser o de $E 1$, a estratégia adotada é repetir literalmente as ideias do autor. O texto de autoria própria (fora das aspas) tampouco revela conexões claras ou a produção de sentido atrelado às ideias de Morin. Então, E1 não atendeu ao solicitado, pois copiou ideias e as comentou de modo tautológico (já que "sentido" e "significado", uma linha abaixo, dizem o mesmo).

Ainda na questão 3, no trecho "trazendo como experiências aquilo que realmente possa formar uma cabeça bem-feita", a utilização do verbo "trazer" induz a pensar ter-se selecionado das experiências elementos necessários à aprendizagem, e apagar aquilo que não serve para tal. As respostas de $E 1$ traduzem uma evidente dificuldade de interpretação da leitura e organização das ideias a serem escritas, permitindo inferir, como consequência, a dificuldade de organização do pensamento.

Para E1, elaborou-se um feedback negativo, antecedido por um positivo, pois o objetivo era corrigir e melhorar o desempenho do aluno diante das dificuldades demonstradas por ele, sem, todavia, deixar de indicar elementos que deveriam ser mantidos - aumentando, por esse reforço específico, as chances de discriminação entre comportamentos a serem conservados e outros a serem modificados. Por isso, precisou-se detalhar as orientações, com vistas a haver progresso na nova tentativa. Com o feedback, reorientou-se o desempenho discente em cada resposta, em forma de comentário diretamente dirigido ao aluno. Vejamos o fornecimento na segunda questão:

Figura 1: Fornecimento de feedback na segunda questão para $E 1^{2}$

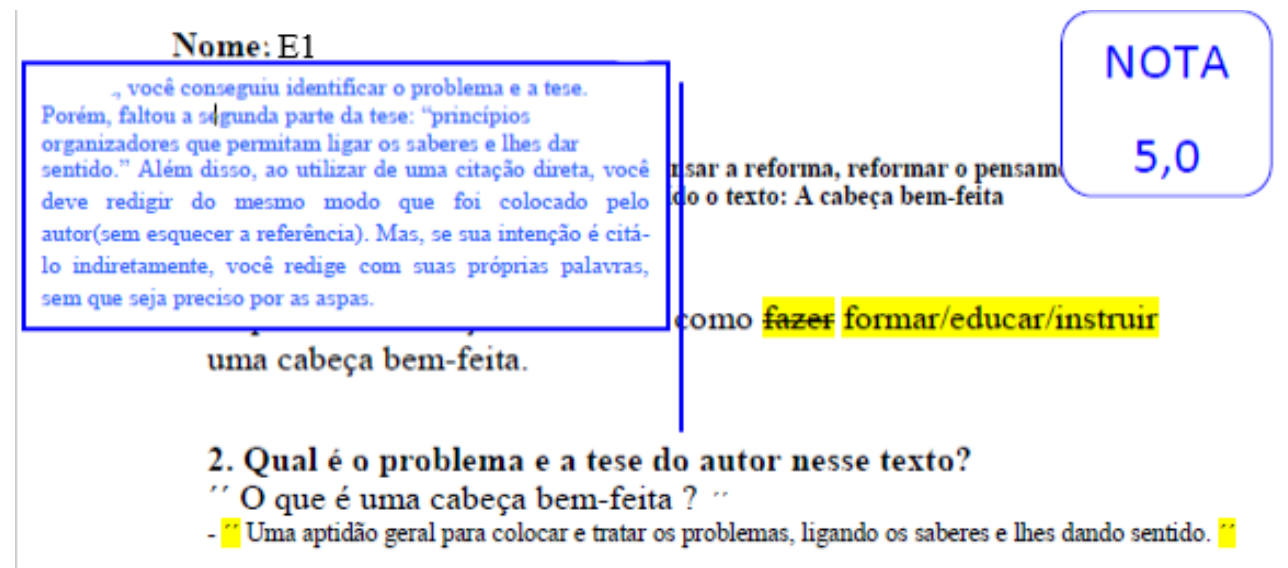

Fonte: Própria autoria.

\footnotetext{
${ }^{2}$ Para melhor entendimento da sobreposição de imagens na Figura 1, cumpre esclarecer que os feedbacks foram apresentados por meio de formas do Word (balões de escrita denominados "textos explicativos"), cujo formato impede a leitura direta do texto original que recebeu o feedback.
} 
Sugeriu-se a $E 1$ rever sua redação, organização das ideias e o aspecto formal (estético) de seu trabalho, mas a nota posterior ao feedback resultou da inexistência de elementos que indicassem uma evolução qualitativa. Em ambos os momentos antes e após o feedback, E1 permaneceu com nota 5,0.

Embora E1 não tenha conseguido avançar em todos os aspectos indicados, refazer a tarefa já demonstra sua consideração do feedback como uma possibilidade de aprender mais e melhorar sua performance. Constatou-se que refazer o exercício indicou o interesse de $E 1$ em melhorar seu desempenho, demonstrando responsabilidade com seu aprendizado.

Nesse caso, quando o resultado não é o esperado conforme o feedback, os fornecedores, nesse caso professor e monitora, precisam fazer uma autorreflexão acerca dos efeitos do instrumento planejado (POERTNER; MILLER, 1996): o modo como o feedback foi detalhado, permitiu ao estudante entender minhas expectativas em relação a performance dele? Essa autoavaliação da prática permitiu à monitora, em sua função discente, vislumbrar a necessidade de adaptação e elaboração do instrumento avaliativo e do feedback de forma clara e significativa ao estudante.

\section{Estudante 3}

Como E1, E3 era estudante assídua nas aulas, bastante participativa nas discussões; diferentemente dele, porém, ela sempre argumentava com segurança, fundamentava sua fala e fazia muitas perguntas. Demonstrava ser bastante inquieta, no questionando e demonstrando a necessidade de buscar mais detalhes para compreender os conteúdos, característica fundamental no processo de construção do conhecimento, sobretudo na disciplina de Filosofia da Educação.

E3 estava já em sua segunda graduação. Seu primeiro curso superior deu-se na área das Ciências Exatas. Nesse sentido, o curso de Pedagogia lhe possibilitava refletir acerca de temas relacionados à realidade, ao contexto social como um sistema aberto, em constantes mudanças e, consequentemente, analisar seus processos de aprendizagem no curso anterior, desenvolvendo-se metacognitivamente. Era um novo universo para E3.

Pode-se vislumbrar essas características na questão 4 de sua síntese de texto:

4. Conexões feitas, você consegue estabelecer alguma relação entre a(s)

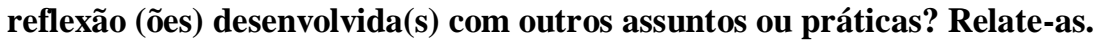




\begin{abstract}
Submeti-me às duas formas de avaliação, primeiro ao PSS, e depois de doze anos ao ENEM. No primeiro processo, tanto pela forma de ensino quanto pela imaturidade, agora percebo que o mais importante era ter uma cabeça bem-cheia, muitos conhecimentos sem, ou com pouquíssimas conexões uns com os outros. $\mathrm{O}$ objetivo era apenas acumular conhecimento e conseguir responder às especificidades e não "escorregar nas cascas de banana", que eram determinantes para a aprovação ou reprovação. Ao me submeter ao ENEM, percebi que minha experiência adquirida durante a vida valia muito, o diferencial nesta avaliação, é ter uma cabeça bem-feita que saiba fazer as conexões entre os conhecimentos. 2- No curso de pedagogia, percebo o grande interesse tanto dos alunos quanto dos professores, de se formarem cabeças bem-feitas. Durante as discussões em sala, sempre são citados conhecimentos adquiridos tanto em outras disciplinas, quanto durante a vida, e com eles sempre são feitas relevantes conexões.
\end{abstract}

Seu desempenho na síntese de texto foi bastante satisfatório. E3 utilizou-se de linguagem clara e objetiva, organização estética e fez ótimas conexões com a realidade, demonstrando compreensão do conteúdo. No primeiro ponto da sua resposta à quarta questão, E3 faz avaliação crítica acerca de dois instrumentos avaliativos diferentes Processo Seletivo Simplificado (PSS) e o Exame Nacional do Ensino Médio (ENEM) mas que conduzem ao mesmo objetivo: o ingresso no ensino superior. Nesse quesito, E3 apropriou-se do conteúdo aprendido para analisar ambos os instrumentos, estabelecendo conexões e atribuindo seu juízo acerca de qual avaliação contemplaria melhor as necessidades formativas da contemporaneidade, segundo o autor estudado no texto sintetizado.

Porém, deixou de aprofundar, em sua reflexão, a relação entre os conceitos apresentados pelo texto-base, o que foi solicitado pelo enunciado da questão 3 ("Quais são as ideias principais? Comente-as."). Ao reproduzir as ideias do autor do texto, sem desenvolvê-las em comentário, E3 deixou, portanto, a desejar nesta resposta, obtendo, na questão, 3,0 (num valor máximo de 4,0 para a questão). No cômputo geral do exercício, a aluna obteve a nota 8,4 .

Figura 2: Fornecimento de feedback na terceira questão a E3

8- Imperativo

A cabeça bem-feita deve ser formada levando-se em consideração os imperativos de cada época, ou seja, os conhecimentos que a sociedade exige que o sujeito tenha, naquele momento. Devem-se haver conexões entre estes conhecimentos de forma que eles sejam úteis para cada ¿, é preciso aprofundar um pouco mais os seus comentários. Além dissso, seria mais interessante comentar as ideias principais com suas próprias palavras!!!

Pontuação 3,0 
Fonte: Própria autoria.

Como se pode observar na Figura 2, o feedback positivo para E3 valorizou sua capacidade de argumentar com objetividade e sua habilidade para fazer conexões. Por sua vez, sugeriu-se que a estudante aprofundasse os comentários acerca das ideias principais, conforme indicado no comentário no canto inferior esquerdo da mesma Figura.

Mesmo com nota acima de 7,0, E3 refez o exercício para melhorar seu desempenho, acatando as orientações do feedback. Na segunda versão do exercício, E3, de fato, fez os comentários solicitados. Todavia, reduziu o número de ideias, o que contribuiu para o aumento de sua nota final, mas não lhe permitiu alcançar a pontuação máxima na questão 3 .

Nas aulas, a monitora e o professor da disciplina receberam um feedback oral de E3 acerca da utilização de feedbacks assim como sua importância na formação profissional. Ela avaliou esse instrumento como proporcionador de diálogo entre professor(a) e aluno(a), diminuindo a distância nesse relacionamento e democratizando o processo de ensino-aprendizagem - realidade totalmente nova e distinta das suas experiências anteriores, não apenas na educação básica ou no curso anterior de graduação, mas também no próprio curso de Pedagogia, noutras disciplinas, em que o comportamento e método de muitos professores e professoras distanciam-se de um ensino compromissado e cuidadoso.

Houve, portanto, uma evolução entre os desempenhos de E3 com a inserção do feedback: ela obteve 8,4 na primeira síntese e 9,2 após o feedback, evolução esta considerável por evidenciar um progresso que a aproximou da nota máxima $(10,0)$.

A melhora de desempenho de E3 está associada à responsabilidade da estudante com a própria aprendizagem. Segundo Poetner e Miller (1996), a pessoa que recebe o feedback precisa responsabilizar-se pelas suas ações, neste caso, o próprio desempenho. Este aspecto contribui para o entendimento de que nem docente nem discente são neutros no processo de ensino-aprendizagem, tampouco responsáveis exclusivos por seus efeitos.

\section{Estudante 5}

Assim como E3, E5 também tinha uma inquietude facilmente perceptível em sua participação nas discussões em sala. Possuía o perfil de aluna falante e questionadora. Costumava anotar em seu caderno tudo o que o professor falava nas aulas em relação ao conteúdo da disciplina. 
Contradizendo seu desempenho em sala, a síntese de texto de E5 foi um dos dois casos, dentre a produção dos vinte e quatro estudantes, no qual se detectou cópia indevida da internet: plágio. O problema foi identificado pelo software específico para esse tipo de procedimento $^{3}$. O programa reconheceu partes de textos de vários sites, dentre os quais o Slide Share (com apresentações em slides de trabalhos variados) foi o mais utilizado. O resultado da análise é apresentado na Figura 1, a seguir:

Figura 3- Resultado da análise produzida pelo software Plagius para a resposta de $E 5$ à questão 4

Conexões feitas, você consegue estabelecer alguma relação entre a(s) reflexão (ões) desenvolvida(s) com outros assuntos ou práticas? Relate-as.

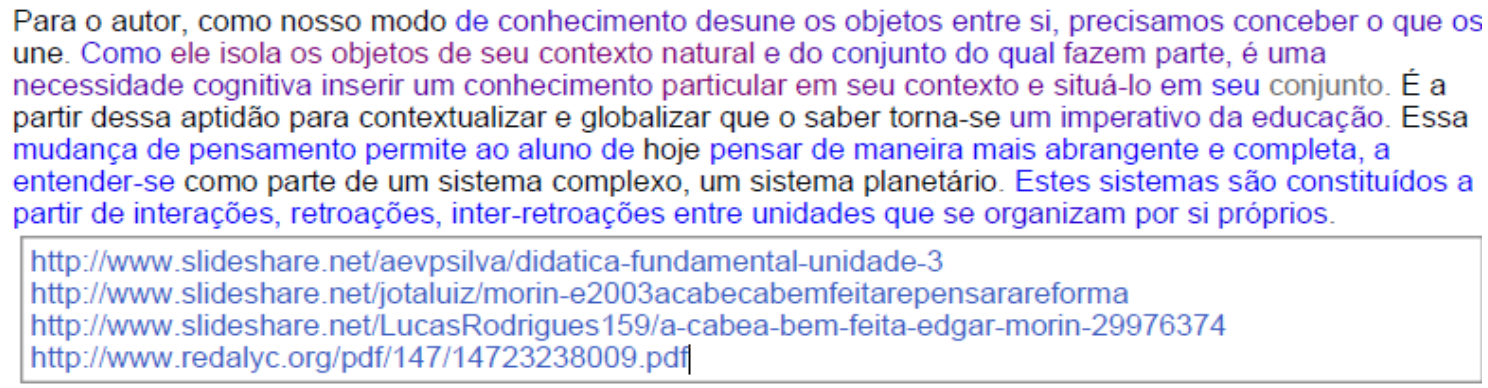

Fonte: Própria autoria.

Como se vê no enunciado, a questão 4 solicitava conexões entre o conteúdo estudado e outros assuntos ou práticas: mesmo assim, E5 demonstrou dificuldade para desenvolver uma resposta de própria autoria, podendo representar a incompreensão do texto de Morin. Nesses casos, percebe-se: o caminho escolhido pela estudante foi ainda mais complicado. Deixou de escrever com palavras próprias uma síntese de suas ideias e compreensão, para selecionar partes de textos distintos, organizá-las num sentindo para tentar responder ao que entendeu ser solicitado na síntese.

No feedback a seu exercício, foi reforçado seu perfil de aluna participativa, com o objetivo de incentivá-la a produzir e expressar sua compreensão com palavras próprias; também houve a orientação, caso precisasse se apoiar em outros textos ou autores, para fazer citações com a devida referência.

\footnotetext{
${ }^{3}$ Plagius - Detector de Plágio foi o software utilizado, que analisa documentos em busca de suspeitas de plágio. O software foi desenvolvido por Gustavo A. Hennig, como trabalho de conclusão do curso de Ciência da Computação, em 2007. Sua versão gratuita é limitada, suportando documentos de até 500 palavras. A versão que oferece licença completa pode ser comprada no site: https://www.plagius.com/br/store.
} 
Figura 4: Fornecimento de feedback no exercício de E5

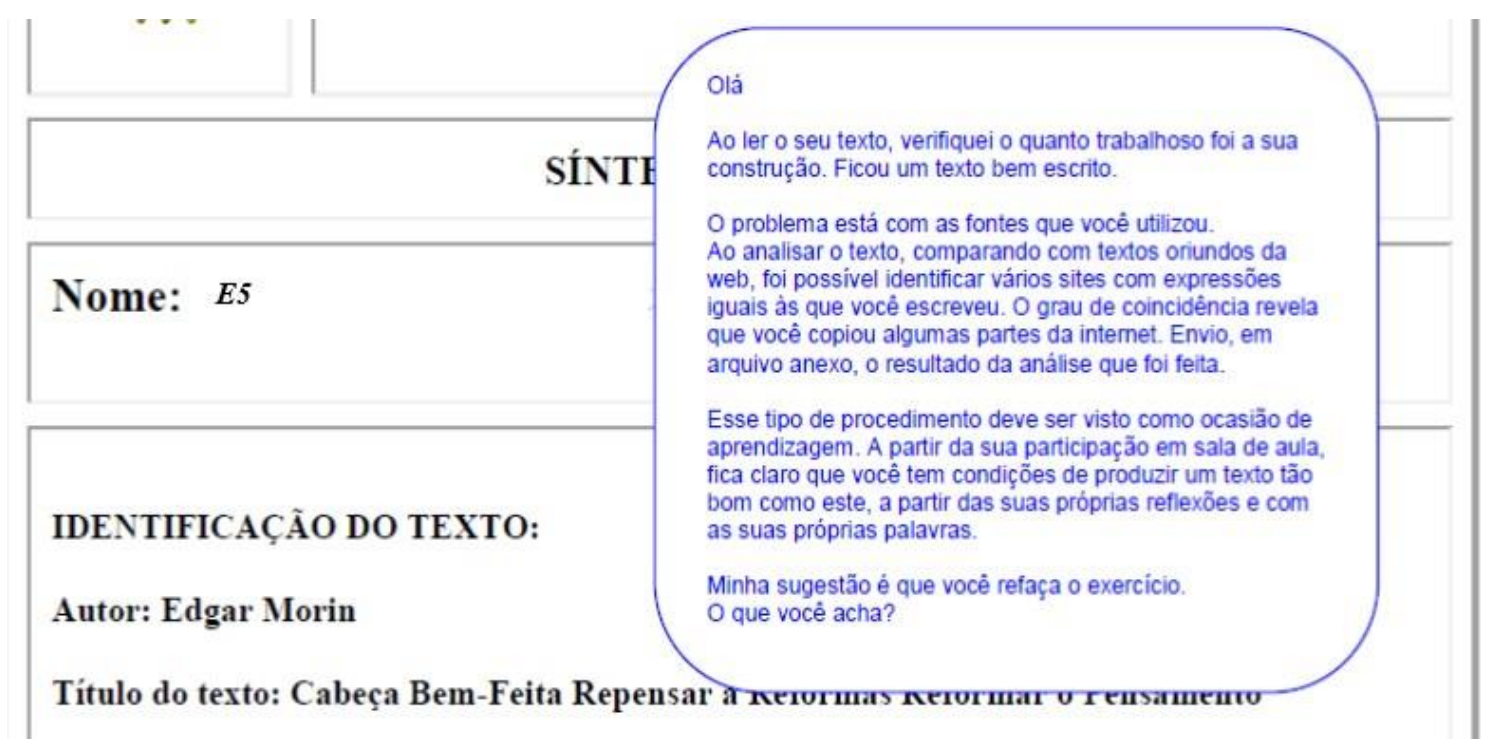

Fonte: Própria autoria.

A nota atribuída ao desempenho de E5 na síntese de texto foi 6,0; por considerar as orientações do feedback e refazer o exercício, E5 alcançou 7,0. Apesar da pouca diferença quantitativa, a estudante evoluiu bastante qualitativamente: no exercício refeito passou a escrever com palavras próprias, representando um avanço significativo, além de ter alcançado, afinal, a média mínima desejada.

O feedback possibilitou tratar pedagogicamente o problema da cópia indevida; permitiu à estudante continuar produzindo; e, ao professor e à monitora, investigar melhor esse comportamento contraditório de uma discente que parecia firme em seus argumentos orais, mas ainda com muita insegurança para registrar suas ideias, como evidenciou a Figura 4.

\section{Considerações finais}

Este artigo teve como intuito evidenciar as contribuições positivas da habilidade social educativa de Dar e Receber Feedback na formação de educadores. Foram escolhidos os desempenhos avaliativos (pré e pós-feedback) de três estudantes participantes da disciplina de Filosofia da Educação, em um curso presencial de Pedagogia de uma universidade pública, com o intuito de aprofundar a análise e incitar novas discussões, as quais ressaltaram o potencial pedagógico dessa habilidade social educativa para o favorecimento de aprendizagens, a depender de sua influência nas contingências de cada indivíduo (seu desempenho em sala de aula, seu histórico acadêmico, sua motivação para 
aprender etc.). Nessas ocasiões, a interação docente-discente, mediada pela habilidade de Dar e Receber Feedback tende a ser valiosa para aperfeiçoar desempenhos - como mostraram dois dos três resultados analisados neste artigo.

O conjunto de dados aqui analisado demonstrou, acerca de Dar e Receber Feedbacks que, se comparada em seus efeitos, essa habilidade social educativa varia contingencialmente, requerendo, portanto, um olhar mais cuidadoso para as especificidades. De fato, o mesmo procedimento (feedback) produziu efeitos distintos (aperfeiçoamento de desempenho, manutenção de desempenho etc.), muito em função de quem o recebeu, de sua história acadêmica e de suas metas.

Não é suficiente, logo, presumir ser aquela habilidade social educativa uniforme e aplicável a qualquer situação indistintamente. Ao contrário, Dar e Receber Feedbacks supõe um estudo das contingências que podem entrar em ação para determinarem efeitos mais desejáveis sobre o aperfeiçoamento ou manutenção do desempenho discente - como provaram, comparativamente, os resultados pós-feedback de E1, E3 e E5.

Portanto, conforme os resultados apresentados e discussões feitas, percebeu-se ter a inserção do feedback na avaliação potencializado o aprendizado e, consequentemente, a formação de todos os envolvidos no relacionamento interpessoal docente-discente. $\mathrm{O}$ feedback proporcionou maiores chances de ensino e aprendizado para o docente, a monitora e discentes, por estabelecer um espaço de horizontalidade e dialética próprios ao planejamento de contingências: a ação do(a) estudante levou o professor e monitora a refletirem sobre suas atuações, reorientando-os para novas ações.

$\mathrm{Na}$ dinâmica desse estudo, professor e monitora foram socialmente habilidosos nos três casos apresentados, ao conseguirem promover ou manter em seus estudantes comportamentos, ações ou desempenhos mais satisfatórios - a julgar pelas notas de $E 3$ e E5 posteriores aos respectivos feedbacks. Isso ajuda a comprovar o cunho relacional, interativo e dialógico estabelecido entre docentes e estudantes. Assim, o(a) professor(a), como agente educativo (DEL PRETTE; DEL PRETTE, 2005) preocupado(a) com o desenvolvimento e aprendizagem de outrem, precisa saber agir com habilidades sociais educativas que lhe permitam gerir satisfatoriamente as relações nesse processo.

Outro aspecto importante: elaborar feedback e orientar novos caminhos para o alcance dos objetivos de aprendizagem requerem do(a) professor(a) o conhecimento seu alunado. Isso está diretamente imbricado no processo avaliativo: só se pode avaliar com coerência aquilo (ou aqueles) que se conhece(m). 
Assim, Dar e Receber Feedback mostrou-se como uma Habilidade Social Educativa fundamental naquele contexto de formação de professores, por colaborar para a qualidade da comunicação no relacionamento professor-alunos, além de possibilitar o desenvolvimento da automonitoria, habilidade social capaz de trazer benefícios para formação profissional e pessoal.

Verificou-se igualmente o feedback dentro do processo educativo permitir, ao (à) professor(a), antecipar os resultados positivos da aprendizagem de determinados conteúdos, ou seja, motivar cada estudante a prosseguir. Um(a) estudante motivado(a) e, consequentemente, com uma autoestima alta aprende mais e melhor, pode-se interpretar.

Por ser constituída como trabalho sobre a interação que se volta para o(a) professor(a), no alcance de seus objetivos por meio de interações com seu alunado, a Pedagogia, como tecnologia da interação, é favorecida pela habilidade social educativa de Dar e Receber Feedback, um desses meios para organizar o ensino e favorecer o alcance dos objetivos de aprendizagem.

\section{Referências}

CARBONELl, J. Pedagogias do século XXI: bases para a inovação educativa. 3. ed., Porto Alegre: Penso, 2016.

DEL PRETTE, Z. A. P.; DEL PRETTE, A. Desenvolvimento interpessoal e educação escolar: o enfoque das habilidades sociais. Temas em Psicologia, 1998, vol. 6, n³ 3, p. 205215. 1999.

Psicologia das habilidades sociais: terapia e educação. Petrópolis, RJ: Vozes,

Psicologia das relações interpessoais: vivências para o trabalho em grupo. Petrópolis, RJ: Vozes, 2001.

Habilidades sociais, desenvolvimento e aprendizagem: questões conceituais, avaliação e intervenção. Campinas, SP: Editora Alínea, 2003.

Vozes, 2005.

Psicologia das habilidades sociais na infância: teoria e prática. Petrópolis, RJ:

Um sistema de categorias de habilidades sociais educativas. Paidéia, v. 18, n. 41, p. 517-530, 2008.

SOARES, Adriana Benevides; PRETTE, Zilda Aparecida Pereira Del. Habilidades sociais e adaptação à universidade: Convergências e divergências dos construtos. Análise Psicológica, Lisboa, v. 33, n. 2, p. 139-151, 2015. Disponível em $<$ http://www.scielo.mec.pt/scielo.php?script=sci_arttext\&pid=S087082312015000200001 $\& \operatorname{lng}=$ pt\&nrm=iso $>$. Acesso em: 05 de maio de 2018. 
DEMO, P. Avaliação: para cuidar que o aluno aprenda. São Paulo; Editora Criarp, 2006.

ELIAS, L. C. S; AMARAL, M. V. Habilidades Sociais, Comportamentos e Desempenho Acadêmico em Escolares antes e após Intervenção. Psico-USF [online]. 2016, vol.21, n.1, pp.49-61. Disponível em: http://www.scielo.br/scielo.php?pid=S141382712016000100049\&script=sci_abstract\&tlng =pt. Acesso em: 01 de junho de 2018.

ÉVORA, Iolanda. Sobre a metodologia qualitativa: experiências em psicologia social. Comunicação apresentado nos Seminários em Psicologia - Universidade Autonomia de Lisboa (29/11/2006). Disponível em: http://pascal.iseg.utl.pt/ cesa/files/publicacoes/OP4.pdf. Acessado em: 26 de outubro de 2015.

MARCHESI, A. O que será de nós, maus alunos? Porto Alegre: Artmed, 2006.

MORIN, E. A cabeça bem-feita; repensar a reforma - reformar o pensamento. Rio de Janeiro: Bertrand Brasil, 2006.

PINOLA, A. R. R.; MARTURANO, E. M.; EliAS, L. C. S.; DEL PRETTE, Z. A. P. Ensinando habilidades sociais educativas para professores no contexto da inclusão escolar. Revista Educação Especial, v. 30, n. 59, p. 737-750, Santa Maria, 2017. Disponível em: https://periodicos.ufsm.br/educacaoespecial. Acesso em: 25 de junho de 2018.

POERTNER, S.; MILLER, K. M.. The Art of Giving and Receiving Feedback. Coastal Training Technologies Corp, Virginia, 1996.

SPENCE, S. H. Social Skills Training with Children and Young People: Theory, Evidence and Practice. Child and Adolescent Mental Health, Volume 8, No. 2, 2003, pp. 84-96. Disponível em: https://onlinelibrary.wiley.com/doi/abs/10.1111/1475-3588.00051. Acesso em: 01 de junho de 2018.

TARDIF, M. O trabalho docente: elementos para uma teoria da docência como profissão de interações humanas. 8. Ed, Petrópolis, Rio de Janeiro: Vozes, 2013.

ZABALA, A. A prática educativa: como ensinar. Porto Alegre: Artmed, 1998.

ZEFERINO, A.; DOMINGUES, R.; AMARAL, E.. Feedback como estratégia de aprendizado no ensino médico. Revista Brasileira de Educação Médica. 2007, 31 (2): 176 - 179. Disponível em: http://www.scielo.br/scielo.php?pid=S010055022007000200009\&script=sci_abstract\&tlng=pt. Acesso em: 30 de agosto de 2015.

Recebido em: 14.10 .2018 Aceito em: 13.02.2019 